\title{
Demineralization Around Restorations with Different Restorative Materials Containing Fluoride
}

\author{
Letícia Caliento Seixas, Fábio Heredia Seixas, Juliane Cristina Ciccone, \\ Wanessa Christine Santos Souza, Regina Guenka Palma-Dibb* \\ Faculdade de Odontologia de Ribeirão Preto \\ Departamento Odontologia Restauradora \\ Av. do Café s/n, Monte Alegre, 14040-904 Ribeirão Preto - SP, Brazil
}

Received: March 14, 2003; Revised: September 29, 2003

\begin{abstract}
The aim of this study was to evaluate in vitro the demineralization on tooth/restoration interface of eight restorative materials after demineralization/remineralization cycling. Eighty class V cavities were prepared with margins at enamel and dentin/cementum, and were restored with Fuji II LC, Fuji IX, Ketac-fil, Ketac Molar, Ariston pHc, Compoglass, Degufill Mineral and Z100. After the restorative procedures, the restorations were submitted to demineralization/ remineralization cycling during 14 days. Specimens were embedded in acrylic resin and submitted to serial sectioning. The sections were examined by optical microscope, and demineralization around restoration was measured on cervical and occlusal margins. The data were analyzed using the ANOVA and Tukey test $(\mathrm{p}<0.05)$. Glass ionomer cements showed less demineralization on enamel and dentin/restoration interfaces when compared to the tested composite resins (Z100 and Degufill Mineral). In conclusion, glass ionomer cements suffered less demineralization but did not protect completely the tooth/restoration interface.
\end{abstract}

Keywords: Glass ionomer cement, Composite resin, Demineralization, Dental enamel, Dentin/ cementum

\section{Introduction}

The bacterial biofilm on restoration margins is one of the main causes of secondary caries. Therefore, it is important to develop methods that prevent its occurrence or decrease its formation on restorations ${ }^{1}$. Several studies ${ }^{2-7}$ showed that fluoride interferes in the dynamics involved in the development of caries and could present an antimicrobial effect or provide demineralization inhibition or dental remineralization.

The idea is that the development of fluoride releasing materials can contribute to a preventive effect in existing carious conditions. However, Chung et al. ${ }^{8}$ found that the amount of fluoride released by the restorative material is an important variable in a cariostatic effect.

The Glass Ionomer Cement (GIC) was developed and presented initially by Wilson and Kent in 1971 and introduced in the world market in the late $70^{\prime} \mathrm{s}^{9}$.
Several factors contributed to the great acceptance of GIC, including ability to take up and release fluoride, biocompatibility and good adhesion to dental substrate ${ }^{10}$. They also present minimal shrinkage on setting and a coefficient of thermal expansion similar to that of tooth structure. However, some characteristics of the first conventional GIC have limited their use for a long time, such as the high technique sensitivity and solubility, water sorption and low mechanical strength. Nowadays, the viscosity of GIC has been altered, thus enlarging its clinical indications, as it has been employed for the atraumatic restorative treatment (ART). The main objectives of ART are to preserve dental structure and provide preventive and curative care to needy populations, in critical situations where there is no access to places adapted for dental treatment ${ }^{11}$.

To decrease the solubility of GIC and to improve its 
aesthetic effect, resinous components were added to the material, mainly the HEMA; this provided to the GIC the characteristics of a double polymerized material, which was called Resin-Modified Glass Ionomer Cement (RMGIC). This new material presents better aesthetics, lower solubility and better adhesion to tooth structure than the conventional GIC, although resulting in a significant decrease of fluoride releasing ${ }^{9,12}$.

In order to give to the composite resins the fluoride releasing ability as in GIC, in the last decade, polyacids were added to the resinous material thus incorporating properties of the composite resins and the conventional ionomer. These new materials, defined as Polyacid-Modified Composite Resins (PMCR), are widely known as "compomers". These materials also release less fluoride than conventional glass ionomers ${ }^{13}$.

The literature presents different results concerning the effect of fluoride released by restorative materials on the demineralization inhibition around restorations. Therefore, further research should be carried out to evaluate the properties of these materials as well as others recently introduced.

The aim of this study was to evaluate in vitro the demineralization around restorations with different restorative materials containing fluoride.

\section{Materials and methods}

Forty sound human molars, extracted within a six-month period and stored in saline solution at $4{ }^{\circ} \mathrm{C}$ were selected and carefully cleaned with hand scales and water/pumice slurry using dental prophylactic cup. The teeth were impacted to standardize the mineralization of the enamel, avoiding teeth with maturation post-eruption.

Eighty class $\mathrm{V}$ cavities with the occlusal margin in enamel and cervical margin in dentin/cementum were prepared using a 329 carbide bur at high speed with air/water spray. Cavity outlines were previously traced onto both buccal and lingual surfaces with a marker pen, determining mesiodistal $4 \mathrm{~mm}$-mesiodistal and $3 \mathrm{~mm}$-occlusalgingival a measure; the depth of the cavity was approximately $2 \mathrm{~mm}$, calibrated by a pre-marked periodontal measuring probe. The cavity finishing was accomplished with a hand instrument.

The cavities were randomly assigned to 8 groups according restorative materials (Table 1). All teeth were identified with different marks, so that the same material did not restore the two cavities on same tooth. Afterwards, the teeth were bisected and separated according to the identifications. The cavities were then restored according to the material specified for each group. The control group was restored with a composite resin without fluoride (Z100).

For Fuji II LC, Ketac-fil and Ketac Molar the cavities were previously treated with a $40 \%$ polyacrylic acid (Durelon liquid, ESPE America Norristown, PA 19404) that was applied on the cavity surfaces with a light scrubbing motion for $10 \mathrm{~s}$ and then rinsed for $20 \mathrm{~s}$. For Fuji IX the surfaces were treated with Fuji IX liquid. The materials were dosed and manipulated according to manufacturer's instructions. The resulting mixture was injected into the cavities using a Centrix injector (Centrix, Shelton, CT 06484, USA) to prevent void and bubble formation. The conventional GIC, were inserted in single increment and the resin-modified GIC (Fuji II LC) was inserted into the cavities in two increments, light-cured for $40 \mathrm{~s}$ each, using a visible lightcuring unit with a $450 \mathrm{~mW} / \mathrm{cm}^{2}$ output (XL 3000, 3M Dental Products, St Paul, MN 55144). For conventional GIC, two layers of colorless nail varnish were applied over the restorations to prevent water loss and uptake, and over Fuji II LC, one layer of bonding agent (Single bond, 3M Dental Products, St Paul, MN 55144) was applied and light-cured for $20 \mathrm{~s}$.

In the cavities restored with Ariston pHC, a layer of Ariston Liner was previously applied, gently dried with oil-free air after $20 \mathrm{~s}$, and light-cured for $20 \mathrm{~s}$. Then Ariston $\mathrm{pHc}$ was inserted with appropriate instruments according to the incremental technique, and each increment was lightcured for $40 \mathrm{~s}$.

In Compoglass group, a first coat of Syntac Single-Component bonding agent was applied with a disposable brush, left undisturbed for $20 \mathrm{~s}$, gently dried and light-cured for $20 \mathrm{~s}$; a second coat was applied following the same steps. Compoglass was inserted according to the incremental technique with a suitable instrument and each layer was lightcured for $40 \mathrm{~s}$.

In the samples restored with Z100, enamel and dentin surfaces were etched with $37 \%$ phosphoric acid gel (gel etchant, Kerr Corporation, Orange, CA 92667) for $15 \mathrm{~s}$, rinsed for $10 \mathrm{~s}$ and gently dried with absorbent paper to remove water excess and to keep tooth surface moist. Afterwards, two layers of Single Bond were applied with a brush over enamel and dentin, gently dried for $5 \mathrm{~s}$ and light-cured for $10 \mathrm{~s}$. The composite resin was inserted with appropriate instruments according to the incremental technique, and each increment, about $1 \mathrm{~mm}$ thick, was light-cured for $40 \mathrm{~s}$.

For Degufill mineral, cavities were dried with oil-free air, and the bonding agent Etch \& Prime 3.0 was used. One drop of Etch \& Prime 3.0 Universal and one drop of catalyst were mixed and applied in two separate layers with a brush over the enamel and dentin surfaces, left for $30 \mathrm{~s}$, spread over with oil-free air until no liquid movement was visible, and then each layer was light-cured for $10 \mathrm{~s}$. The restorative material was inserted with an appropriate instrument according to the incremental technique and each increment was light-cured for $40 \mathrm{~s}$. 
Table 1. Specification, composition and manufacturers of the tested materials.

\begin{tabular}{|c|c|c|}
\hline Restorative System/Batch/Ratio P:L & Type/Composition & Manufacturer \\
\hline $\begin{array}{l}\text { Fuji II LC } \\
\# 02091\end{array}$ & $\begin{array}{l}\text { RMGIC/P: aluminum-fluorosilicate glass L: water, } \\
\text { polyacrilic acid and HEMA; }\end{array}$ & $\begin{array}{l}\text { GC corporation } \\
\text { Tokyo, 174-8585 Japan }\end{array}$ \\
\hline \multicolumn{3}{|l|}{$3.2: 1.0$} \\
\hline Ketac - fil & Conventional GIC/ P: St-Al-La fluorosilicate glass. & ESPE-Premier Corp. \\
\hline \#FW0050630 & L: tartaric acid, copolymer acid and water.; & Norristown, PA 19404 \\
\hline $3.2: 1.0$ & & \\
\hline
\end{tabular}

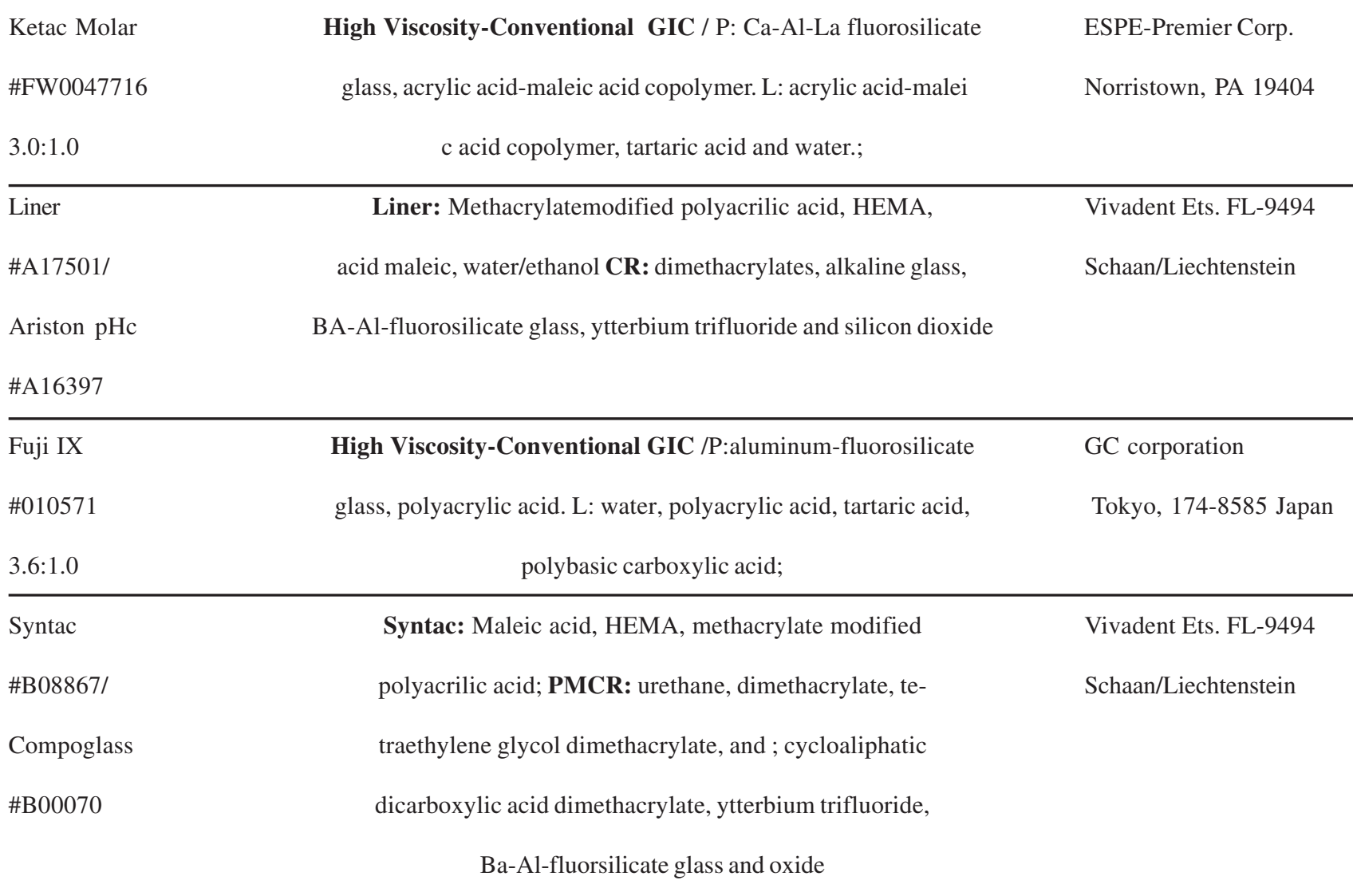

\begin{tabular}{lcc}
\hline Single Bond & Adhesive: Ethanol, HEMA, polyalkenoic copolymer, & 3 S St. Paul, MN \\
\#9DK/ & Bis-GMA, dimethacrylate, water. CR: Bis-GMA, TEGDMA; & 55144 USA \\
Z100 \#9RG & Adhesive: Tetra-methacrilatepyrophosphate, HEMA/ & Degussa-Hüls AG \\
$\begin{array}{l}\text { Etch \& Prime } \\
\text { \#3992003/ }\end{array}$ & HEMA, ethanol,water. CR: Bis-GMA methacrylates, & Postfach 1364 \\
$\begin{array}{l}\text { Degufill Mineral } \\
\text { \#303-2 }\end{array}$ & silicon dioxide, B-Al-Ba silicate, Ca-phosphate-fluoride-aptite & D-63403 Hanau \\
\hline
\end{tabular}


For all restorations, the finishing procedures were accomplished by removing the roughest excesses with a 12 surgical blade, and the final polishing was carried out with Super Snap discs (SHOFU INC. Kyoto 605-0983, Japan) in decreasing abrasive order.

Then, the teeth were isolated with nail varnish, leaving a $2 \mathrm{~mm}$ space around the tooth/restoration interface. The artificial caries was realized using a dynamic model of demineralization and remineralization simulating in vivo highrisk conditions to caries, similar to the one presented by Featherstone et al. ${ }^{14}$ (1986) and modified by Serra \& $\operatorname{Cury}^{15}(1992)$.

The demineralization solution $(\mathrm{pH}=4.3)$ consisted of $2.0 \mathrm{mmol} / \mathrm{l}$ of $\mathrm{Ca}, 2.0 \mathrm{mmol} / \mathrm{l}$ of phosphate in buffer solution of acetate $0.075 \mathrm{~mol} / 1$, and the remineralization solution ( $\mathrm{pH}=7.0$ ) consisted of $1.5 \mathrm{mmol} / \mathrm{l}$ of $\mathrm{Ca}, 0.9 \mathrm{mmol} / \mathrm{l}$ of phosphate, $150 \mathrm{mmol} / \mathrm{l}$ of potassium chloride.

The teeth were submitted to 14 cycles of demineralization and remineralization. Each cycle consisted the immersion of the hemi tooth in $5 \mathrm{ml}$ of demineralization solution for $6 \mathrm{~h}$, washing with $5 \mathrm{ml}$ of deionized water and immersion in $5 \mathrm{ml}$ of remineralization solution for $18 \mathrm{~h}$. The specimens were cycled during 14 days.

After this period, the nail varnish was removed, the radicular portion was sliced and the specimens were embedded in acrylic resin (JET, Clássico, São Paulo, SP 05458-001). The restorations were sectioned longitudinally in a bucolingual direction with a diamond saw in a Minitom sectioning machine (Struers A/S, Copenhagen, Denmark), providing two cuts of $1.0 \mathrm{~mm}$ thick for each tooth. The sections were initially thinned in a polishing machine (Politriz, Struers A/S, Copenhagen, Denmark) using 280 to 600 grit silicon carbide paper, and then manually smoothed with 1000 and $1200 \mathrm{SiC}$ paper to obtain a flat surface and a final thickness of approximately $0.25 \mathrm{~mm}$. The cuts were then identified, carefully fixed on microscopic slides and the demineralization was assessed in millimeters by view- ing them under a $2.5 \times$ magnification optical microscope (Axioskope-Zeiss) connected to a color video camera (TK-1270, JVC) with a $10 \times$ magnification lens. The images obtained were transmitted to a personal computer and after digitization were analyzed using the KS300-v2.0 software (Kontron Elektronik), which performs a standard assessment of the demineralization level extension along the interfaces (enamel/restoration and cementum/dentin/restoration), and allows a quantitative measurement in millimeters. The means of the demineralization level extension for enamel and dentin-interfaces were calculated for each group. Two gauged examiners analyzed all the restorations for measurement standardization.

The data were analyzed for distribution and subjected to statically analysis using ANOVA and Tukey test at a 0.05 significance level.

\section{Results}

The analysis of the data showed that all the examined teeth examined exhibited superficial demineralization presenting different degrees of mineral lost.

There was statistically significant difference among the evaluated margins $(\mathrm{p}<0.01)$; the cementum/dentin margin showed higher degree of demineralization and structure loss (cavity formation) than to the enamel margin.

Significant difference $(\mathrm{p}<0.05)$ was noted among the tested materials, and the most evident results of demineralization inhibition were observed in dental tissues adjacent to cavities restored with glass ionomer cements. In those restorations, no loss of enamel structure was observed, but there was tissue loss on cementum/restoration interface in approximately $40 \%$ of the samples.

The means and standard deviation are shown in Table 2.

Structural loss was observed on the enamel and dentin/cementum interfaces in all specimens restored with Z100 and Degufil Mineral composite resins. The difference between these two resins, considering the deminer-

Table 2. Means and standard deviation (SD) of demineralization depth $(\mathrm{mm})$ at enamel and dentin/cementum margins of restorations with the tested materials.

\begin{tabular}{lcc}
\hline Material & $\begin{array}{c}\text { Margins } \\
\text { Enamel }(\text { SD })\end{array}$ & Dentin/Cementum $($ SD) \\
\hline Fuji II LC & $0.116( \pm 0.036) \mathrm{a}$ & $0.171( \pm 0.032) \mathrm{cde}$ \\
Ketac-fil & $0.121( \pm 0.028) \mathrm{ab}$ & $0.169( \pm 0.039) \mathrm{cde}$ \\
Ketac Molar & $0.135( \pm 0.030) \mathrm{abc}$ & $0.214( \pm 0.039) \mathrm{fg}$ \\
Ariston pHc & $0.145( \pm 0.020) \mathrm{abc}$ & $0.192( \pm 0.077) \mathrm{def}$ \\
Fuji IX & $0.156( \pm 0.032) \mathrm{bcd}$ & $0.236( \pm 0.049) \mathrm{gh}$ \\
Compoglass & $0.173( \pm 0.060) \mathrm{cde}$ & $0.238( \pm 0.116) \mathrm{gh}$ \\
Z100 & $0.202( \pm 0.040) \mathrm{efg}$ & $0.261( \pm 0.061) \mathrm{h}$ \\
Degufill Mineral & $0.240( \pm 0.054) \mathrm{gh}$ & $0.388( \pm 0.080) \mathrm{i}$ \\
\hline
\end{tabular}


alization degree on both margins, was statistically significant $(\mathrm{p}<0.05)$, being smaller than those restored with Z100.

Ketac Molar presented similarity to Ariston. For both materials there was structure loss in half of the specimens at cervical margin (cementum/dentin).

Fuji IX and Compoglass presented intermediate results and statistical similarity, although for Compoglass there was larger substrate loss at cementum/restoration interface than compared to Fuji IX.

\section{Discussion}

Recurrent caries is one of the main reasons for restoration replacement ${ }^{16-19}$. Several studies ${ }^{13,20,21}$ have shown that restorative materials containing fluoride can minimize the recurrence of caries around restoration. It is thought that fluoride release by restorative materials may contribute to the inhibition of demineralization on the tooth/restorative material interface.

The fluoride presence and its release give to the material a cariostatic effect. However, an appropriate amount of released fluoride is required in order to obtain a more beneficial effect ${ }^{21}$. Several works ${ }^{15,22}$ have used a system of induction of artificial caries to evaluate the cariostatic effect of the used restorative materials. The present study used a dynamic simulation model of demineralization and remineralization simulating in vivo high-risk conditions to caries.

The level of fluoride release by the restorative materials seems to be an important factor in resistance to caries and in the formation of a demineralization inhibition $z o n e^{21}$. The mechanism of fluoride release by GIC is similar to that by silicate, presenting a continuous release, which tends to peak $24 \mathrm{~h}$ after the mixing started. Forss \& Seppä ${ }^{23}$ demonstrated that the fluoride release by ionomers could increase the amount of fluoride ions in the bacterial biofilm that is in contact with the material.

The fluoride release by glass ionomer cement varies specially if resinous monomers are added to its composition, decreasing it significantly. Even so, in some cases, there is no difference in the caries inhibition zones, because of some factors, such as other ions liberation and material composition, could be more significant and present stronger influence to the inhibition of artificial caries than the amount of fluoride released ${ }^{21}$.

Demineralization was observed in all specimens, and all materials permitted, to some degree, mineral and structural loss, mainly at the cementum/dentin margins. Even so, on the surfaces surrounding glass ionomers cement restorations generally occurred lower demineralization degree and smaller structural loss at enamel and dentin/cementum margins than Degufill Mineral and Z100 composite resins.
Earlier investigations ${ }^{5,20}$ have disclosed that GIC has a higher cariostatic and demineralization inhibition potential than composite resin.

Laboratory evaluations of the tested materials showed that Ketac-fil provides higher fluoride release than Ketac Molar and Compoglass ${ }^{24}$. In the present study, it was noticed higher demineralization at cementum/dentin margin with these two materials than with Ketac-fil. Therefore, the fluoride release amount variation among the tested materials seems to be an important variable in the demineralization inhibition.

It was observed that the RMGIC (Fuji II LC) presented similar results the conventional GIC (Ketac-fil), even so it provided lightly larger inhibition effect than the other tested ionomeric cements. These observations are supported by previous study ${ }^{16}$.

The benefit of fluoride incorporation to composite resin has been reported, even if its concentration or release may not be sufficient to inhibit the demineralization resulting from acid attack ${ }^{21}$. In the conducted research, it was noticed that no demineralization inhibition occurred with Degufill Mineral composite resin this material showed smaller cariostatic effect than the resin without fluoride (Z100).

Compoglass and Ariston $\mathrm{pHc}$ showed less demineralization than the control (Z100). These results are similar to those obtained by Chung et al. ${ }^{8}$, which evaluated the materials ability to inhibit the demineralization at enamel. Compoglass and Ariston also presented similar results to high viscosity conventional glass ionomer cements, mainly at the cementum/dentin margin ${ }^{11}$ In addition, it was observed that Compoglass showed a demineralization depth at enamel comparable to Ketac Molar and Fuji IX. In the present study, difference was found only for Ketac Molar, which showed smaller demineralization degree; Compoglass and Fuji IX were statistically similar. Millar et $a l .{ }^{13}$ showed similar results to with these materials in a previous investigation.

Under the conditions of this study, the glass ionomer cements permitted smaller enamel and dentin/cementum structural loss, demonstrating to be well indicated for high risk to caries situations. However, further researches, mainly clinical evaluations, are required to assess the effectiveness of these materials.

\section{Conclusions}

Based on the results of the conducted study, and within the limitations of an in vitro study, it may be concluded that:

- The cementum/dentin margin presented higher demineralization degree than the enamel margin;

- Ketac-fil and Fuji II LC glass ionomer cements pro- 
vided less demineralization at tooth/restoration interface in an acidic environment, suggesting that these materials are well indicated for high risk to caries situations.

\section{Acknowledgements}

The authors acknowledge financial support provided by FAPESP (grant 99/09337-9).

\section{References}

1. Kawai, K.; Heaven, T.J.; Retief, D.H. Journal of Dentistry, v. 25, n. 3-4, p. 291-296, 1997.

2. Donly, K.J.; Nelson, J.J. Journal of Dentistry for Childre, v. 64, n. 4, p. 249-250, 1997.

3. Forsten, L. Biomaterials, v.19, n.6, p.503-508, 1998. 4. Griffin, F.; Donly, K.J.; Erickson, R. American Journal of Dentistry, v. 5, n. 6, p. 293-295, 1992 .

5. Hara, A.T. et al. Pesquisa Odontológica Brasieira, v. 14, n. 2, p. 113-118, 2000.

6. Kawai, K. et al. Caries Research, v. 32, n. 6, p. 463-469, 1998.

7. Khouw-Liu, V.H.W.; Anstice, H.M.; Pearson, G.J. Journal of Dentistry, v. 27, n. 5, p. 351-357, 1999.

8. Chung, C.K. et al. Journal of Dentistry, v. 26, n. 5-6, p. 533-538, 1998.

9. Navarro, M.F.L.; Palma, R.G.; Del'Hoyo, R.B. In: Feller, C.; Bottino, M.A. Atualização na clínica odontológica. A prática da clínica geral. Editora Artes Médicas,SP, Brasil, p. 61-74. 1994.

10. Barnes, D.M.; Blank, L.W. Journal of American Dental
Association, v. 126, p. 1245-1253, 1995.

11. Smales, R.J.; Gao, W. Journal of Dentistry, v. 28, n. 4, p. 249-256. 2000.

12. Sidhu, S.K.; Watson, T.F. American Journal of Dentistry, v. 8, p. 59-67, 1995.

13. Millar, B.J.; Abiden, F.; Onicholson, J.W. Journal of Dentistry, v. 26, n. 2, p. 133-136, 1998.

14. Featherstone, J.D.B. et al. In: LEACH, S.A. Factors relating to demineralization and remineralization of the teeth, Oxford IRL, p. 23-34, 1986.

15. Serra, M.C.; Cury, J.A. Quintessence International, v. 23, n. 2, p. 143-147, 1992.

16. Dunne, S.M.; Goolnik, J.S.; Millar, B.J.; Seddon, R.P. Journal of Dentistry, v. 24, n. 1-2, p. 291-294, 1996.

17. Fontana, M. General Dentistry, v. 43, n. 2, p. 143-154, 1995.

18. Kidd, E.A. Advances in Dental Research, v. 4, p. 10-13, 1990.

19. Özer, L.; Thylstrup, A. Advances in Dental Research, v. 9, n. 4, p. 394-402, 1995.

20. Palma, R.G. et al. RPG Revista da Pós-Graduação da FOUSP, v. 3, n. 3, p. 203-208, 1996.

21. Pereira, P.N.R.; Inokoshi, S.; Tagami, J. Journal of Dentistry, v. 26, n. 5-6, p. 505-510, 1998.

22. Serra, M.C.; Rodrigues, A.L. Revista da Associação Paulista de Cirurgiões Dentistas, v. 52, n. 5, p. 359364, 1998.

23. Forss, H.; Seppä, L. Advances in Dental Research, v. 9 , n. 4, p. 389-393, 1995.

24. Shaw, A.J.; Carrick, T.; McCabe, J.F. Journal of Dentistry, v. 26, n. 4, p.355-359, 1998. 